\title{
Cardiovascular and Gastrointestinal Effects of Etoricoxib in the Treatment of Osteoarthritis: A Systematic Review and Network Meta-analysis
}

\author{
Dam Kim, Soo-Kyung Cho ${ }^{1}$, Seoung Wan Nam ${ }^{1}$, Hyuk Hee Kwon', Sun-Young Jung ${ }^{2}$, Chan Hong Jeon, \\ Seul Gi Im ${ }^{4}$ Dalho Kim ${ }^{4}$, Eun Jin Jang ${ }^{5}$, Yoon-Kyoung Sung ${ }^{1}$ \\ 'Department of Rheumatology, Hanyang University Hospital for Rheumatic Diseases, ${ }^{2}$ College of Pharmacy, Chung-Ang University, Seoul, \\ ${ }^{3}$ Division of Rheumatology, Department of Internal Medicine, Soon Chun Hyang University Bucheon Hospital, Bucheon, ${ }^{4}$ Department of \\ Statistics, Kyungpook National University, Daegu, ${ }^{5}$ Department of Information Statistics, Andong National University, Andong, Korea
}

\begin{abstract}
Objective. To estimate the cardiovascular (CV) and gastrointestinal (GI) risks of etoricoxib in the treatment of osteoarthritis (OA) compared to a placebo and other non-steroidal anti-inflammatory drugs (NSAIDs). Methods. A systematic review of randomized, controlled trials (RCTs) of etoricoxib were performed. Bayesian network meta-analysis was used over a duration of 12 weeks. The incidence of CV and Gl events for a duration $\geq 26$ weeks were also tabulated and presented using descriptive statistics. Results. From this search, 10 studies were identified. Of these, 6 and 5 RCTs that measured the CV and GI events at 12 weeks were included in meta-analysis. They showed that etoricoxib did not increase the CV events compared to the placebo or NSAIDs during the 12 week period (odds ratio $[O R]=0.59$ compared to celecoxib, $O R=0.89$ with ibuprofen, $O R=0.70$ with placebo, and $\mathrm{OR}=2.16$ with naproxen). The risk of Gl events was comparable to that of most comparators, with the exception of naproxen, which had a significantly lower risk of $G$ l events $(O R=0.18)$ during the 12 week period. For a duration $\geq 26$ weeks, the incidence of $\mathrm{CV}$ and Gl events with etoricoxib increased with increasing duration. Conclusion. Etoricoxib is an alternative short-term treatment option for OA, showing comparable CV and GI complications to other NSAIDs. Nevertheless, further studies will be needed to elucidate the long-term safety of etoricoxib in the treatment of OA. (J Rheum Dis 2017;24:293-302)
\end{abstract}

Key Words. Anti-inflammatory agents, non-steroidal, Etoricoxib, Osteoarthritis, Safety

\section{INTRODUCTION}

Osteoarthritis (OA) is the most common joint disorder, affecting $70 \%$ of individuals older than 55 years [1]. For treatment of $\mathrm{OA}$, non-steroidal anti-inflammatory drugs (NSAIDs) are the mainstay for reducing pain and inflammation, although detailed recommendations are different according to treatment guidelines [2-5]. However, since $\mathrm{OA}$ is a chronic disease and affects mainly patients with advanced age, safety profiles of medications are as important as their effectiveness.

Non-selective NSAIDs, which inhibit both cyclooxygenase (COX)-1 and COX-2, are well known to cause severe gastrointestinal (GI) adverse events [6,7]. With many risk factors for development of GI adverse events such as old age, concomitant use of other medication for comorbidities, and long duration of NSAID use, OA patients have increased risk of GI adverse events [6]. Therefore, the use of selective COX-2 inhibitors, which are safer in terms of GI adverse events, has been quickly adopted for treatment of OA [8]. However, another safety concern arose because of the high selectivity of COX-2, which might be associated with higher risk of cardiovascular (CV) events [9-11].

Etoricoxib, which is a relatively new COX-2 inhibitor, is known to be an effective and safe treatment option for ar-

Received : August 31, 2017, Revised : October 7, 2017, Accepted : October 8, 2017

Corresponding to : Yoon-Kyoung Sung, Department of Rheumatology, Hanyang University Hospital for Rheumatic Diseases, 222 Wangsimni-ro, Seongdong-gu, Seoul 04763, Korea. E-mail : sungyk@hanyang.ac.kr 
thritis patients, and it is now approved in several countries in Europe and Asia [12]. Several previous studies compared the safety of COX-2 inhibitors including etoricoxib with nonselective NSAIDs $[13,14]$. However, they did not take into account the duration and dose of etoricoxib, which is an important issue for development of adverse events.

In this study, we aimed to estimate CV and GI risks of etoricoxib in treatment of OA compared with placebo and other NSAIDs according to duration and dose of medication.

\section{MATERIALS AND METHODS}

\section{Literature search}

We performed a systematic literature review of randomized controlled trials (RCTs) of etoricoxib in patients with OA of the hand, knee, hip, or spine. A computerized search of electronic databases from their inception to September 12, 2017 was performed in MEDLINE, EMBASE, and CENTRAL database of Cochrane Library. Search terms are provided in Supplementary Table 1. Our search included only human subjects and articles written in English.

\section{Selection criteria}

RCTs that evaluated the CV or GI safety of etoricoxib compared with placebo or other NSAIDs in adults with $\mathrm{OA}$ of any site for a duration of six weeks or longer were included in this study. Eligible studies included those where osteoarthritis was diagnosed based on clinical decision. We excluded trials that studied post-operative safety and trials that included patients with inflammatory arthritis such as rheumatoid arthritis. We also excluded studies that compared the CV and GI safety of etoricoxib and opioids. Finally, we excluded trials that did not report relevant safety outcomes adjudicated by independent expert Case Review Committees. Three authors (DK, SWN, and HHK) independently reviewed the search results for eligible studies. Disagreements were resolved by discussion and consensus.

\section{Outcome measures}

The outcomes of interest were thrombotic CV adverse events and upper GI adverse events during treatment with etoricoxib or a comparator. We examined the numbers of patients with thrombotic CV adverse events such as myocardial infarction and ischemic cerebrovascular ac- cident in cardiovascular, cerebrovascular, and peripheral vascular beds. We also extracted the numbers of patients with upper GI adverse events including perforation, ulcer, and bleeding. All potential serious CV and GI adverse events included in this analysis were adjudicated by separate, blinded expert case review committees.

\section{Data extraction and assessment of bias}

We extracted participant characteristics of age, site of $\mathrm{OA}$, and treatment duration, as well as aspects of the study including number of patients and dose and times per day. In addition, interventions were divided into an etoricoxib group and a comparators group including placebo, diclofenac, celecoxib, ibuprofen, and naproxen. In order to evaluate safety outcomes, use of low dose aspirin and gastroprotective agents was noted. Relevant safety outcomes were collected as number of CV and GI adverse events during treatment duration.

For this study, we utilized the Cochrane Collaboration's tool for assessment of risk of bias in order to assess study quality [15]. Each study was scored as high risk, low risk, or unclear risk of bias in seven domains: random sequence generation, allocation concealment, blinding of participants and personnel, blinding of outcome assessment, incomplete outcome data, selective reporting, and other bias. Other bias was including design-specific risks of bias, early stopping for benefit, severe baseline imbalances, and inappropriate influence of funders.

Three authors (DK, SWN, and HHK) independently extracted data and assessed bias; any disagreement was resolved by discussion and consensus.

\section{Ethical considerations}

The study protocol was approved by the Institutional Review Board (IRB) of Hanyang University (IRB no. 2016-06-008).

\section{Statistical analysis}

This study focused on relatively rare adverse events. In general, if there are zero cells in dichotomous outcome, a continuity correction is required to calculate the odds ratio (OR) or relative risk. However, corrections for zero cell counts are not necessary when using Peto's method [16]. Because of zero cell counts of CV adverse events and GI adverse events, we considered the Peto's OR as the effect size.

To compare the risk of adverse events for etoricoxib with the risk for each NSAID or placebo with therapy duration 
of 12 weeks, network meta-analysis was performed. Network meta-analysis is a method of combining direct evidence and indirect evidence to estimate the pairwise treatments effect, and frequentist or Bayesian approaches are possible. The Bayesian method combines likelihood with a prior distribution to obtain a posterior probability distribution [17] and allows probability statements to be made directly regarding quantity of interest; for example, OR is more than 1 ( $\mathrm{P}[\mathrm{OR}>1]$ ) [18]. In addition, the Bayesian hierarchical random-effects model was used to account for the clinical and methodological heterogeneity between included studies. We assumed a normal likelihood distribution for the logarithm of Peto's OR and noninformative uniform prior distribution for standard deviation between trials.

There are two assumptions for conducting network meta-analysis. The similarity assumption requires that the included study populations are similar in effect modifiers such as age, disease severity, and disease duration [19]. We compared the baseline characteristics of each study and the adverse event incidence in the etoricoxib group to verify the similarity assumption. The consistency assumption that the direct estimate is consistent with indirect estimates is another main assumption in a network meta-analysis, and this assumption was assessed using the node-splitting method [20].

We presented the posterior median and $95 \%$ credible interval (CrI) for OR and the posterior probability that OR is more than $1(\mathrm{P})$. $\mathrm{P}$ of at least $90 \%$ signifies increased risk of etoricoxib over NSAIDs or placebo, and $\mathrm{P}$ less than $10 \%$ indicates that etoricoxib had a lower risk than NSAIDs or placebo. The parameters were estimated using the Markov Chain Monte Carlo (MCMC) algorithm in WinBUGS Version 1.4.3 (MRC Biostatistics Unit, Cam- bridge, UK), and the convergence of the MCMC algorithm was assessed using trace plot, autocorrelation plot, and Gelman-Rubin statistics. We discarded the first 10,000 iterations in order to eliminate the initial value effect, and 50,000 iterations were performed in two chains for estimation of the posterior distribution. In the sensitivity analysis, we applied inverse-gamma or normal noninformative prior distribution for the variance between trials in order to assess the robustness of results.

In addition, we performed subgroup analysis in patients with OA of the hip and knee joint to evaluate whether etoricoxib had different adverse events compared with patients with OA of any site. Moreover, subgroup analysis according to dose of etoricoxib was also performed to identify the dose effect of etoricoxib for CV and GI events. Since the number of studies involving treatment duration of 26 weeks or longer was small, and studies did not meet the homogeneity assumption, the incidence of CV and GI events in therapy duration of 26 weeks or longer was tabulated and presented using descriptive statistics.

\section{RESULTS}

\section{Study characteristics}

Among 371 RCTs searched using multiple electronic searches, 48 full texts were assessed for eligibility after excluding 323 studies by screening title and abstract. A final 10 studies were included in our study after further reviewing full texts [21-30]: eight were excluded because they were not RCTs, three were without peer review, seven involved non-OA patients, one did not involve etoricoxib, 16 reported no outcome of interest, two did not utilize adequate comparators, and one was excluded for other reasons (Figure 1).

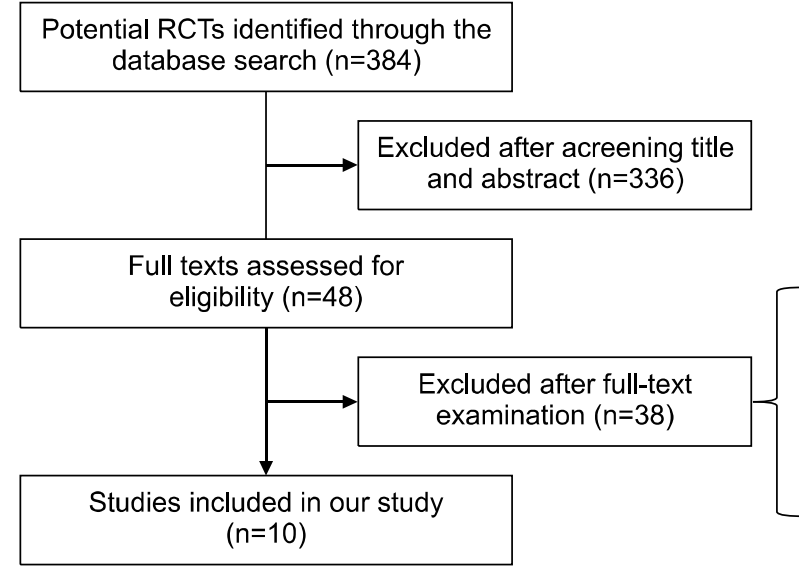

Non RCT ( $n=8)$

Without peer review $(n=3)$

Not osteoarthritis patients $(n=7)$

Without etoricoxib $(n=1)$

Without outcome interest $(n=16)$

Without adequate comparator $(n=2)$ Figure 1. Study selection flow. Other $(n=1)$
RCT: randomized controlled trial. 
We included 10 trials of etoricoxib compared with placebo or one of four types of NSAID: celecoxib, diclofenac, ibuprofen, and naproxen, involving 12,588 participants. The trial patient sample size varied from 239 to 7,111 , and the mean age of subjects ranged from 58.3 to 63.7 years. Among them, 6 and 5 RCTs were found that measured CV and GI events at 12 weeks for inclusion, hence we synthesized data from these studies as base case analyses. Four studies had follow-up duration longer than 26 weeks, while the heterogeneity in the length of follow-up and data reporting, led us to the decision not to perform a quantitative analysis. The other study was not included in either analysis because this RCT by Gottesdiener et al. [25] was conducted with placebo- and active comparator in order; Part I (6 weeks) with placebo and Part 2 (8 weeks) with diclofenac (Table 1, Supplementary

Table 1. Characteristics of studies included in this analysis

\begin{tabular}{|c|c|c|c|c|c|c|c|c|c|c|}
\hline \multirow[b]{2}{*}{ Study } & \multirow{2}{*}{$\begin{array}{l}\text { Mean } \\
\text { patient } \\
\text { age }(y r)\end{array}$} & \multirow{2}{*}{$\begin{array}{c}\text { Site of } \\
\text { osteoar- } \\
\text { thritis } \\
\text { included }\end{array}$} & \multirow{2}{*}{$\begin{array}{l}\text { Treatment } \\
\text { duration }\end{array}$} & \multicolumn{2}{|c|}{ Etoricoxib group } & \multicolumn{3}{|c|}{ Comparator } & \multicolumn{2}{|c|}{$\begin{array}{l}\text { Other medication } \\
\text { allowed }\end{array}$} \\
\hline & & & & Number & $\begin{array}{l}\text { Dose* } \\
\text { times }\end{array}$ & Medication & Number & $\begin{array}{c}\text { Dose* } \\
\text { times }\end{array}$ & $\begin{array}{l}\text { Low } \\
\text { dose } \\
\text { aspirin }\end{array}$ & $\begin{array}{l}\text { Gastro- } \\
\text { potective } \\
\text { agents }\end{array}$ \\
\hline $\begin{array}{r}\text { Baraf et al., } \\
2007 \text { [21] }\end{array}$ & 63.7 & $\begin{array}{l}\text { Knee, hip, } \\
\text { hand, } \\
\text { or spine }\end{array}$ & $11 \sim 16 \mathrm{mo}$ & 3,593 & $90 \mathrm{mg} * 1$ & Diclofenac & 3,518 & $50 \mathrm{mg} * 3$ & Yes & Yes \\
\hline $\begin{array}{l}\text { Bingham } \\
\text { et al., } \\
2007 \text { [22] }\end{array}$ & 62.1 & Knee or hip & $26 w k$ & 475 & $30 \mathrm{mg} * 1$ & Celecoxib & 4872 & $200 \mathrm{mg} * 1$ & Yes & Unknown \\
\hline $\begin{array}{l}\text { Cannon } \\
\text { et al., } \\
2008 \text { [23] }\end{array}$ & 58.3 & $\begin{array}{l}\text { No } \\
\text { description } \\
\text { about site }\end{array}$ & $12 \mathrm{wk}$ & 108 & $90 \mathrm{mg} * 1$ & $\begin{array}{l}\text { Celecoxib } \\
\text { Ibuprofen } \\
\text { Placebo }\end{array}$ & $\begin{array}{l}107 \\
107 \\
111\end{array}$ & $\begin{array}{l}200 \mathrm{mg} * 2 \\
800 \mathrm{mg} * 3\end{array}$ & No & Unknown \\
\hline $\begin{array}{c}\text { Curtis et al., } \\
2005 \text { [24] }\end{array}$ & 61.7 & Knee & $46 \mathrm{wk}$ & $\begin{array}{l}198 \\
102 \\
148\end{array}$ & $\begin{array}{l}30 \mathrm{mg} * 1 \\
60 \mathrm{mg} * 1 \\
90 \mathrm{mg} * 1\end{array}$ & Diclofenac & 102 & $150 \mathrm{mg}$ & No & Unknown \\
\hline $\begin{array}{l}\text { Gottesdiener } \\
\text { et al., } \\
2002[25]^{*}\end{array}$ & 61.3 & Knee & $\begin{array}{r}8 w k \\
\text { (Part II) }\end{array}$ & $\begin{array}{l}117 \\
114 \\
102 \\
112 \\
112 \\
198 \\
102 \\
148\end{array}$ & $\begin{array}{l}5 \mathrm{mg} * 1 \\
10 \mathrm{mg} * 1 \\
30 \mathrm{mg} * 1 \\
60 \mathrm{mg} * 1 \\
90 \mathrm{mg} * 1 \\
30 \mathrm{mg} * 1 \\
60 \mathrm{mg} * 1 \\
90 \mathrm{mg} * 1\end{array}$ & Diclofenac & 102 & $50 \mathrm{mg} * 3$ & No & Unknown \\
\hline $\begin{array}{l}\text { Leung et al., } \\
2002 \text { [26] }\end{array}$ & 63.2 & Knee or hip & $12 \mathrm{wk}$ & 224 & $60 \mathrm{mg} * 1$ & $\begin{array}{l}\text { Naproxen } \\
\text { Placebo }\end{array}$ & $\begin{array}{r}221 \\
56\end{array}$ & $500 \mathrm{mg} * 2$ & Unknown & Yes \\
\hline $\begin{array}{l}\text { Puopolo } \\
\text { et al., } \\
2007 \text { [27] }\end{array}$ & 62.6 & Knee or hip & $12 \mathrm{wk}$ & 224 & $30 \mathrm{mg} * 1$ & $\begin{array}{l}\text { Ibuprofen } \\
\text { Placebo }\end{array}$ & $\begin{array}{l}213 \\
111\end{array}$ & $800 \mathrm{mg} * 3$ & Yes & Yes \\
\hline $\begin{array}{l}\text { Reginster } \\
\text { et al., } \\
2007 \text { [28] }\end{array}$ & 62.8 & Knee or hip & $\begin{array}{l}12 w k \\
40 w k \\
86 w k\end{array}$ & $\begin{array}{l}446 \\
434 \\
246\end{array}$ & $\begin{array}{l}60 \mathrm{mg} * 1 \\
60 \mathrm{mg} * 1 \\
60 \mathrm{mg} * 1\end{array}$ & $\begin{array}{l}\text { Naproxen } \\
\text { Placebo } \\
\text { Naproxen } \\
\text { Naproxen }\end{array}$ & $\begin{array}{l}439 \\
112 \\
404 \\
217\end{array}$ & $\begin{array}{l}1,000 \mathrm{mg} * 1 \\
1,000 \mathrm{mg} * 1 \\
1,000 \mathrm{mg} * 1\end{array}$ & Yes & Yes \\
\hline $\begin{array}{l}\text { Wiesenhutter } \\
\text { et al., } 2005 \\
\text { [29] }\end{array}$ & 61.7 & Knee or hip & $12 \mathrm{wk}$ & 214 & $30 \mathrm{mg} * 1$ & $\begin{array}{l}\text { Ibuprofen } \\
\text { Placebo }\end{array}$ & $\begin{array}{l}210 \\
104\end{array}$ & $800 \mathrm{mg} * 3$ & Yes & Yes \\
\hline $\begin{array}{l}\text { Yoo et al., } \\
2014 \text { [30] }\end{array}$ & 63.0 & Knee & $12 \mathrm{wk}$ & 120 & $30 \mathrm{mg} * 1$ & Celecoxib & 119 & $200 \mathrm{mg} * 1$ & Yes & Unknown \\
\hline
\end{tabular}

*This two-part, randomized controlled trial was conducted with placebo- and active comparator in order. Part I (6 weeks), patients received placebo, etoricoxib 5, 10, 30, 60 or 90 mg once daily. In Part II (8 weeks), patients received etoricoxib 30, 60 or 90 mg once daily or diclofenac $50 \mathrm{mg}$ three times a day, predetermined at Part I allocation. 
Tables 2 and 3).

The risk of bias in the majority of domains was very low: blinding of outcome assessment domain (risk of bias "low" 10/10) and incomplete outcome data domain (risk of bias "low" 10/10). However, the risk of bias was high in the other bias domain (risk of bias "high" 10/10) since all included studies were sponsored by the pharmaceutical company that produces etoricoxib (Supplementary Figure 1).

\section{Risk of cardiovascular adverse events of etoricoxib}

During follow-up periods, 58 and $51 \mathrm{CV}$ adverse events occurred in the etoricoxib groups and comparator groups, respectively. The network of treatment comparisons from the included trials is shown in Figure 2A.

In OA of any included site, etoricoxib did not increase the risk of $\mathrm{CV}$ events compared with comparators during 12 weeks $(\mathrm{OR}=0.70,95 \% \mathrm{CrI}=0.12 \sim 3.89, \mathrm{P}=0.34$ compared with placebo, $\mathrm{OR}=0.59,95 \% \mathrm{CrI}=0.03 \sim$ 11.86, $\mathrm{P}=0.36$ compared with celecoxib, $\mathrm{OR}=0.89,95 \%$ $\mathrm{CrI}=0.12 \sim 6.49, \mathrm{P}=0.45$ with ibuprofen, and $\mathrm{OR}=2.16$, $95 \% \mathrm{CrI}=0.19 \sim 25.18, \mathrm{P}=0.74$ with naproxen) (Figure $3 \mathrm{~A})$. The results were consistent when we included studies of patients with OA of the hip or knee joints over a duration of 12 weeks $(\mathrm{OR}=0.65,95 \% \mathrm{CrI}=0.08 \sim 4.91$, $\mathrm{P}=0.33$ with placebo, $\mathrm{OR}=0.99,95 \% \mathrm{CrI}=0.01 \sim 95.15$, $\mathrm{P}=0.50$ with celecoxib, $\mathrm{OR}=0.84,95 \% \mathrm{CrI}=0.07 \sim 10.07$, $\mathrm{P}=0.44$ with ibuprofen, $\mathrm{OR}=2.11,95 \% \mathrm{CrI}=0.14 \sim 31.37$, $\mathrm{P}=0.72$ with naproxen) (Figure $3 \mathrm{~B}$ ) [26-30]. In analysis according to dose of etoricoxib, $30 \mathrm{mg}$ of and $60 \mathrm{mg}$ or higher dose of etoricoxib did not increase the risk of $\mathrm{CV}$ events compared with comparators during 12 weeks (Figure 3C). The results of sensitivity analysis using different prior distributions were consistent with the results of the base case.

After 26 weeks, the incidence of CV events in the etoricoxib group had a tendency to increase according to treatment duration $(0.21 \%$ at 26 weeks, $1.14 \%$ at $11 \sim 16$ months, $2.59 \%$ at 138 weeks) (Supplementary Table 2). In addition, the incidence of $\mathrm{CV}$ events was more than double that found with naproxen in a study of treatment for 138 weeks $(2.59 \%$ in etoricoxib vs. $1.21 \%$ in naproxen) [28]. However, among these studies, we could not find any tendency of $\mathrm{CV}$ event incidence with dose of etoricoxib (data not shown).

\section{Risks of gastrointestinal adverse events of etoricoxib} In the 10 studies included in this analysis, 40 and $67 \mathrm{GI}$ adverse events occurred in the etoricoxib groups and comparator groups, respectively. The network of treatment comparisons from included trials is shown in Figure 2B.

During 12 weeks of treatment, the risk of GI events was comparable to that found with other comparators $(\mathrm{OR}=0.38,95 \% \mathrm{CrI}=0.03 \sim 4.28, \mathrm{P}=0.21$ compared with placebo, $\mathrm{OR}=0.94,95 \% \mathrm{CrI}=0.04 \sim 20.35, \mathrm{P}=0.49$ with celecoxib and $\mathrm{OR}=0.49,95 \% \mathrm{CrI}=0.03 \sim 7.21, \mathrm{P}=0.29$ with ibuprofen), while the risk of GI events was significantly lower than that found with naproxen $(\mathrm{OR}=0.18$, $95 \% \mathrm{CrI}=0.03 \sim 1.17, \mathrm{P}=0.03$ ) (Figure $4 \mathrm{~A}$ ). Among studies that included patients with $\mathrm{OA}$ of the lower extremities and involved treatment of 12 weeks, etoricoxib showed
A

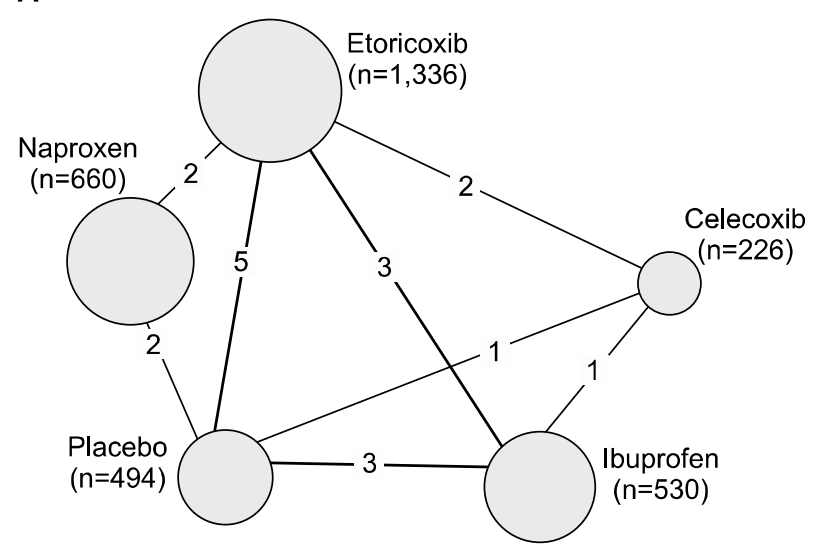

B

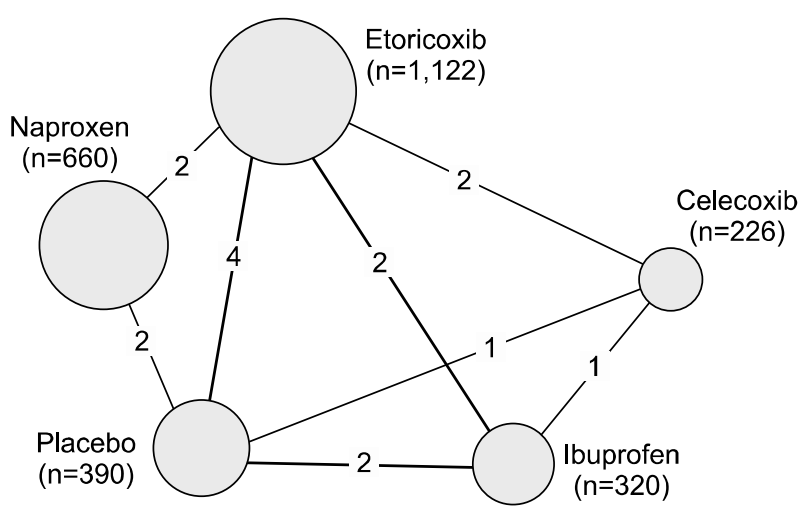

Figure 2. Network of comparisons with a 12-week treatment duration included in the meta-analyses. Lines represent comparison between two medication, and numbers on the line stand for the number of studies. (A) Cardiovascular events. (B) Gastrointestinal events. 
A

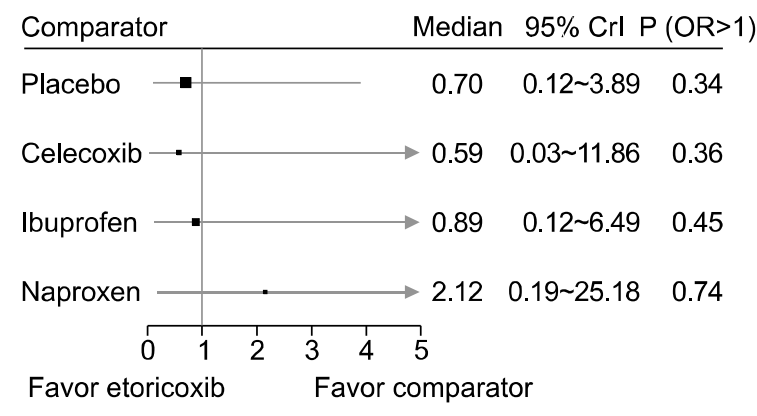

\section{B}

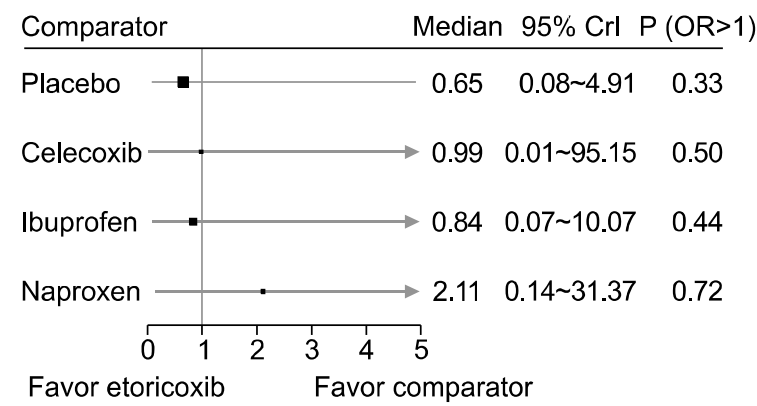

C

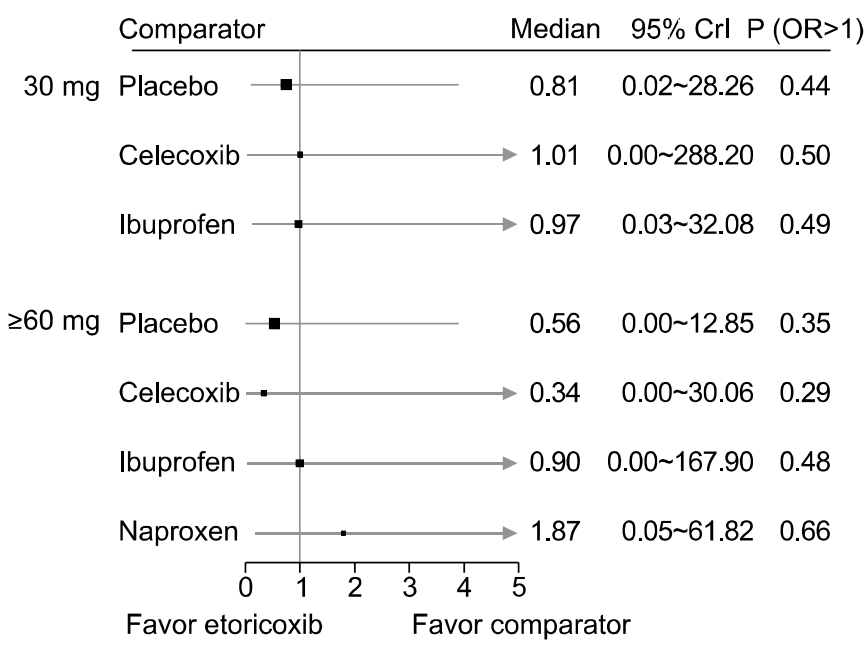

Figure 3. Estimates of cardiovascular events of etoricoxib compared with NSAIDs and placebo in osteoarthritis of any site (A), osteoarthritis of lower extremities (B), and subgroup analysis according to dose (C) with a duration of 12 weeks. NSAIDs: non-steroidal anti-inflammatory drugs, Crl: credible interval, $\mathrm{P}(\mathrm{OR}>1)$ : posterior probability that the odds ratio $(\mathrm{OR})$ is higher than 1.

significantly lower risk of GI events compared with naproxen $(\mathrm{OR}=0.18,95 \% \mathrm{CrI}=0.01 \sim 2.73, \mathrm{P}=0.06)$, while there was no significant difference compared with placebo, celecoxib, and ibuprofen $(\mathrm{OR}=0.24,95 \% \mathrm{CrI}=0.01 \sim$ 6.07, $\mathrm{P}=0.18$ with placebo, $\mathrm{OR}=0.99,95 \% \mathrm{CrI}=0.01 \sim$ 162.70, $\mathrm{P}=0.50$ with celecoxib, $\mathrm{OR}=0.33,95 \% \mathrm{CrI}=0.00 \sim$ 20.83, $\mathrm{P}=0.27$ with ibuprofen) (Figure $4 \mathrm{~B}$ ) [26-30]. In analysis according to dose of etoricoxib, $30 \mathrm{mg}$ of etoricoxib showed comparable risk of GI events with celecoxib, ibuprofen and placebo during 12 weeks. However, in $60 \mathrm{mg}$ or higher dose etoricoxib, etoricoxib showed significantly lower risk of GI events compared with naproxen ( $\mathrm{OR}=0.19,95 \% \mathrm{CrI}=0.01 \sim 3.15, \mathrm{P}=0.07)$, while the risk of GI events for etoricoxib were comparable with celecoxib, ibuprofen, and placebo (Figure 4C). The results of sensitivity analysis using different prior distributions were consistent with the results of the base case.

With a treatment duration of 26 weeks or longer, the incidence of GI events in the etoricoxib group increased with treatment duration $(0.21 \%$ at 26 weeks, $0 \% \sim 0.68 \%$ at 46 weeks, $1.34 \%$ at $11 \sim 16$ months, and $1.39 \%$ at 138 weeks) (Supplementary Table 3). In addition, the incidence of GI events increased with dose of etoricoxib
( $0.15 \%$ in $30 \mathrm{mg}, 1.16 \%$ in $60 \mathrm{mg}$, and $1.31 \%$ in $90 \mathrm{mg}$ of etoricoxib). In a study that compared etoricoxib therapy to naproxen therapy over a treatment duration of 138 weeks, the incidence of GI events in the etoricoxib group was approximately $1 / 4$ of that occurring in the naproxen group ( $1.39 \%$ in etoricoxib vs. $4.85 \%$ in naproxen) [28].

\section{Subgroup analysis of studies allowed to use aspirin} Meta-regression was performed to identify the effect of aspirin use on the CV events and GI events. Since CV event was significant in this analysis, we performed subgroup analysis limited to 4 studies which were allowed to use aspirin. For these studies, the $\mathrm{CV}$ events of etoricoxib during 12 weeks were consistent with base case analysis $(\mathrm{OR}=0.79,95 \% \mathrm{CrI}=0.09 \sim 9.52, \mathrm{P}=0.42$ with placebo, $\mathrm{OR}=1.02,95 \% \mathrm{CrI}=0.01 \sim 803.70, \mathrm{P}=0.50$ with celecoxib, $\mathrm{OR}=1.03,95 \% \mathrm{CrI}=0.08 \sim 14.47, \mathrm{P}=0.51$ with ibuprofen, $\mathrm{OR}=5.26,95 \% \mathrm{CrI}=0.12 \sim 3142, \mathrm{P}=0.80$ with naproxen).

\section{DISCUSSION}

In this study, we reviewed the risk of CV and GI events 
A

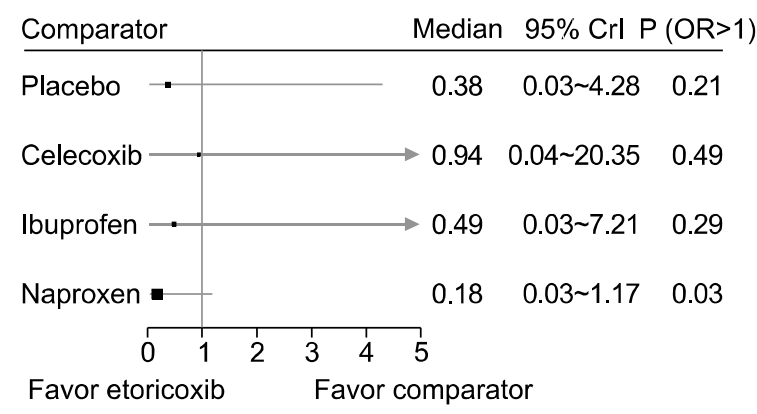

\section{B}

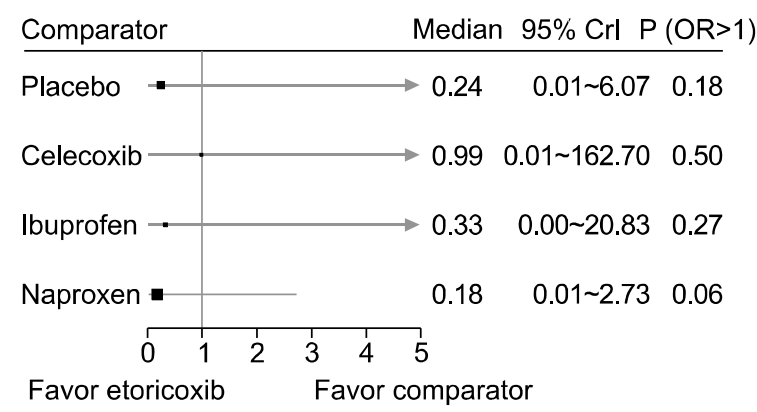

C

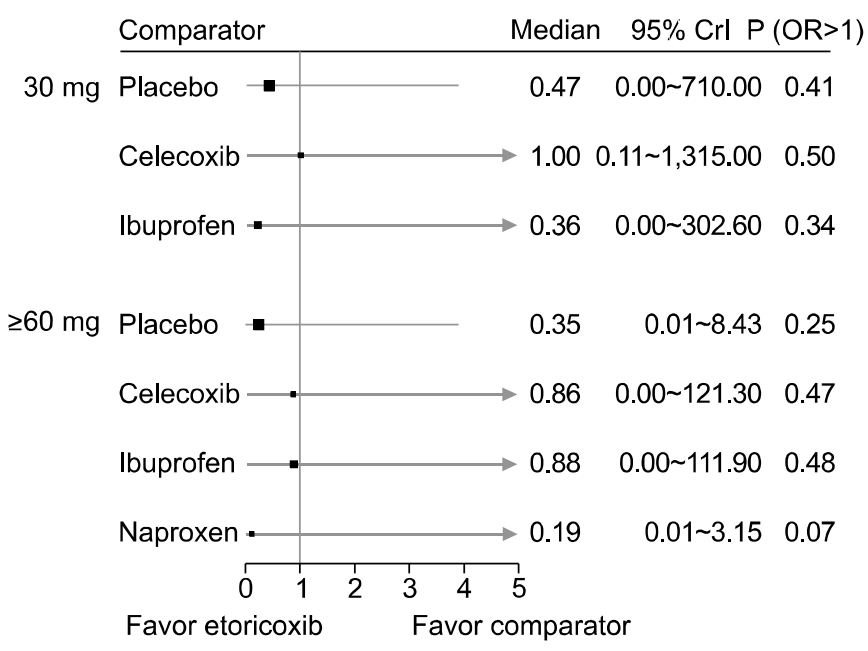

Figure 4. Estimates of gastrointestinal events of etoricoxib compared with NSAIDs and placebo in osteoarthritis of any site (A), osteoarthritis of lower extremities (B), and subgroup analysis according to dose (C) with a treatment duration of 12 weeks. NSAIDs: non-steroidal anti-inflammatory drugs, Crl: credible interval, $\mathrm{P}(\mathrm{OR}>1)$ : posterior probability that the odds ratio (OR) is higher than 1.

resulting from use of etoricoxib compared with placebo or other NSAIDs. In a relatively short treatment duration of 12 weeks, etoricoxib was found to be safe in terms of CV and GI events compared with the other treatments, irrespective of doses. In addition, the risk of GI events was significantly lower in etoricoxib compared with naproxen, which is one of the widely used non-selective NSAIDs. However, in studies with longer treatment duration, both $\mathrm{CV}$ and GI adverse events increased with treatment duration, although statistical significance was not confirmed. It is well known that COX-2 inhibitors significantly reduce the risk of GI events compared to non-selective NSAIDs [6,31]. However, concern about increased risk of CV events with COX-2 inhibitors exists. Several COX-2 inhibitors have been withdrawn or not approved for use due to increased CV risk [9,32]. Researchers have determined that increased risk of $\mathrm{CV}$ and cerebrovascular events is associated with highly selective COX-2 inhibitors [11,33].

Etoricoxib, which is a relatively new and potent selective COX-2 inhibitor, is known to have comparable efficacy to non-selective NSAIDs and better GI safety for arthritis patients. Etoricoxib is a highly selective COX-2 inhibitor and does not inhibit COX-1 at clinical doses, resulting in significantly lower risk of GI events than found with non-selective NSAIDs [34]. However, the high selectivity of COX-2 in etoricoxib is still of concern due to potential higher risk of $\mathrm{CV}$ events.

This study found etoricoxib to be as safe as other comparators (placebo, celecoxib, ibuprofen, and naproxen) regarding $\mathrm{CV}$ events in a short treatment duration. Thus, etoricoxib is a safe alternative to non-selective NSAIDs, with comparable efficacy over a short treatment duration. Etoricoxib was also safe regarding $\mathrm{CV}$ events in various doses even in high dose of $60 \mathrm{mg}$ or higher. However, treatment durations of 26 weeks or longer resulted in more adverse $\mathrm{CV}$ events. Considering that $\mathrm{CV}$ events significantly increased compared with placebo use from 18 months' duration in a previous study comparing rofecoxib and placebo [9], our results that CV events of etoricox$\mathrm{ib}$ were significantly increased only with longer treatment duration are acceptable. Although we did not demonstrate statistical significance because of the small number of studies, the long-term CV safety of etoricoxib is very important. Patients with OA are usually older in age and likely to have several comorbidities including $\mathrm{CV}$, cere- 
brovascular diseases, and many other conditions that can increase the risk of $\mathrm{CV}$ events. Moreover, $\mathrm{OA}$ is a chronic disease that requires long-term medical treatment. Therefore, more research about the long-term $\mathrm{CV}$ safety of etoricoxib is needed, especially for OA patients.

In addition, etoricoxib was as safe as other comparators in term of GI events. Moreover, compared with naproxen, etoricoxib was significantly safer regarding GI events. This can be explained by the characteristics of naproxen, which is a non-selective NSAID with greater COX-1 selectivity. Gastrointestinal events also increased with treatment duration, and it seemed that a higher dose of etoricoxib resulted in more GI events, although the number of studies was not large enough to reach a statistical conclusion. Because OA patients are also vulnerable to GI events due to their long-term use of NSAIDs and concomitant medication such as aspirin, anti-coagulants, and steroids, the increased risk of etoricoxib when used in high doses over long durations must be confirmed.

Several points of this study are worth noting. First, we defined clear inclusion and exclusion criteria, as well as outcome assessments, in order to draw reliable conclusions. Because many of the studies reviewed had different outcome definitions, it was impossible to synthesize and produce definitive conclusions. Therefore, we adopted a strict definition that was adjudicated by independent expert case review committees. Second, different from previous studies, we presented the incidence of CV and GI events over a longer period of time according to dose and treatment duration. Although we could not demonstrate statistical significance with longer duration, we suggest the risk and significance of $\mathrm{CV}$ adverse events with long-term use of etoricoxib, especially in OA patients.

There were some limitations in this study. First, only 10 RCTs were included, although all RCTs conducted after the approval of etoricoxib were collected. Because of the small number of RCTs, it was not possible to divide the $\mathrm{CV}$ and GI events according to site and severity of occurrence. One observational study and one single arm study were included, but these studies did not describe the safety outcome of interest and so were not included $[35,36]$. Second, meta-analysis was performed only with studies of short duration. Since studies of relatively longer treatment duration did not adhere to the homogeneity or similarity assumption, descriptive statistics were used for qualitative analysis. However, it seems that the risk of CV and GI events increase depending on duration of etoricoxib use, and more studies are needed to conclude the long-term CV and GI safety of etoricoxib. Third, since adverse events are limited in number, meta-analysis should be performed carefully. In the classic meta-analysis, when there are no events in either arm of a study, it is omitted from the analysis as it provides no information about the relative effect [37]. In this study, we applied a Bayesian hierarchical random-effects model, which can borrow strength from other studies; thus, we included studies with no events in either arm [18]. In addition, the primary outcomes of RCTs included in this study were not safety of etoricoxib, therefore, the power of safety outcome in individual studies could be low. Fourth, although the risk of bias in studies included in this analysis was relatively low, the bias caused by sponsor is unneglectable. For an accurate and fair estimation of safety, further studies are needed in the future.

\section{CONCLUSION}

Etoricoxib showed comparable CV and GI complications to non-selective NSAIDs and can be considered as an alternative short-term treatment option for OA. However, further studies are needed to elucidate the long-term safety of etoricoxib in the treatment of OA.

\section{ACKNOWLEDGMENTS}

This research was supported by a grant of the Korea Health Technology R\&D Project through the Korea Health Industry Development Institute (KHIDI), funded by the Ministry of Health \& Welfare, Republic of Korea (grant number: $\mathrm{HC15C3388).}$

\section{CONFLICT OF INTEREST}

No potential conflict of interest relevant to this article was reported.

\section{SUPPLEMENTARY DATA}

Supplementary data can be found with this article online at http://www.jrd.or.kr and at https://doi.org/10.4078/ jrd.2017.24.5.293.

\section{REFERENCES}

1. Elders MJ. The increasing impact of arthritis on public health. J Rheumatol Suppl 2000;60:6-8. 
2. Hochberg MC, Altman RD, April KT, Benkhalti M, Guyatt G, McGowan J, et al. American College of Rheumatology 2012 recommendations for the use of nonpharmacologic and pharmacologic therapies in osteoarthritis of the hand, hip, and knee. Arthritis Care Res (Hoboken) 2012;64:46574.

3. Jordan KM, Arden NK, Doherty M, Bannwarth B, Bijlsma JW, Dieppe P, et al. EULAR Recommendations 2003: an evidence based approach to the management of knee osteoarthritis: Report of a Task Force of the Standing Committee for International Clinical Studies Including Therapeutic Trials (ESCISIT). Ann Rheum Dis 2003;62:1145-55.

4. McAlindon TE, Bannuru RR, Sullivan MC, Arden NK, Berenbaum F, Bierma-Zeinstra SM, et al. OARSI guidelines for the non-surgical management of knee osteoarthritis. Osteoarthritis Cartilage 2014;22:363-88.

5. Jevsevar DS. Treatment of osteoarthritis of the knee: evidence-based guideline, 2nd edition. J Am Acad Orthop Surg 2013;21:571-6.

6. Wolfe MM, Lichtenstein DR, Singh G. Gastrointestinal toxicity of nonsteroidal antiinflammatory drugs. N Engl J Med 1999;340:1888-99.

7. Gabriel SE, Jaakkimainen L, Bombardier C. Risk for serious gastrointestinal complications related to use of nonsteroidal anti-inflammatory drugs. A meta-analysis. Ann Intern Med 1991;115:787-96.

8. Dannhardt G, Kiefer W. Cyclooxygenase inhibitors--current status and future prospects. Eur J Med Chem 2001;36: 109-26.

9. Bresalier RS, Sandler RS, Quan H, Bolognese JA, Oxenius B, Horgan K, et al. Cardiovascular events associated with rofecoxib in a colorectal adenoma chemoprevention trial. $\mathrm{N}$ Engl J Med 2005;352:1092-102.

10. Solomon DH, Avorn J, Stürmer T, Glynn RJ, Mogun H, Schneeweiss S. Cardiovascular outcomes in new users of coxibs and nonsteroidal antiinflammatory drugs: high-risk subgroups and time course of risk. Arthritis Rheum 2006; 54:1378-89.

11. Abraham NS, El-Serag HB, Hartman C, Richardson P, Deswal A. Cyclooxygenase-2 selectivity of non-steroidal anti-inflammatory drugs and the risk of myocardial infarction and cerebrovascular accident. Aliment Pharmacol Ther 2007;25:913-24.

12. Croom KF, Siddiqui MA. Etoricoxib: a review of its use in the symptomatic treatment of osteoarthritis, rheumatoid arthritis, ankylosing spondylitis and acute gouty arthritis. Drugs 2009;69:1513-32.

13. van Walsem A, Pandhi S, Nixon RM, Guyot P, Karabis A, Moore RA. Relative benefit-risk comparing diclofenac to other traditional non-steroidal anti-inflammatory drugs and cyclooxygenase- 2 inhibitors in patients with osteoarthritis or rheumatoid arthritis: a network meta-analysis. Arthritis Res Ther 2015;17:66.

14. Gunter BR, Butler KA, Wallace RL, Smith SM, Harirforoosh $\mathrm{S}$. Non-steroidal anti-inflammatory drug-induced cardiovascular adverse events: a meta-analysis. J Clin Pharm Ther 2017;42:27-38.

15. Higgins JP, Altman DG, Gøtzsche PC, Jüni P, Moher D, Oxman AD, et al. The Cochrane Collaboration's tool for assessing risk of bias in randomised trials. BMJ 2011;343: d5928.
16. Higgins JPT, Green S, eds. Cochrane handbook for systematic reviews of interventions version 5.1. 0 [updated March 2011] [Internet]. London: The Cochrane Collaboration [cited 2017 Sep 12]. Available from: http://handbook-5-1.cochrane. org/

17. Hoaglin DC, Hawkins N, Jansen JP, Scott DA, Itzler R, Cappelleri JC, et al. Conducting indirect-treatment- comparison and network-meta-analysis studies: report of the ISPOR Task Force on Indirect Treatment Comparisons Good Research Practices: part 2. Value Health 2011;14: 429-37.

18. Sutton AJ, Abrams KR. Bayesian methods in meta-analysis and evidence synthesis. Stat Methods Med Res 2001;10: 277-303.

19. Jansen JP, Fleurence R, Devine B, Itzler R, Barrett A, Hawkins $\mathrm{N}$, et al. Interpreting indirect treatment comparisons and network meta-analysis for health-care decision making: report of the ISPOR Task Force on Indirect Treatment Comparisons Good Research Practices: part 1. Value Health 2011;14:417-28.

20. Dias S, Welton NJ, Caldwell DM, Ades AE. Checking consistency in mixed treatment comparison meta-analysis. Stat Med 2010;29:932-44.

21. Baraf HS, Fuentealba C, Greenwald M, Brzezicki J, O'Brien K, Soffer B, et al. Gastrointestinal side effects of etoricoxib in patients with osteoarthritis: results of the Etoricoxib versus Diclofenac Sodium Gastrointestinal Tolerability and Effectiveness (EDGE) trial. J Rheumatol 2007;34:408-20.

22. Bingham CO 3rd, Sebba AI, Rubin BR, Ruoff GE, Kremer J, Bird S, et al. Efficacy and safety of etoricoxib $30 \mathrm{mg}$ and celecoxib $200 \mathrm{mg}$ in the treatment of osteoarthritis in two identically designed, randomized, placebo-controlled, non-inferiority studies. Rheumatology (Oxford) 2007;46:496-507.

23. Cannon CP, Chen C, Curtis SP, Viscusi J, Ahmed T, Dibattiste PM. A comparison of cardiovascular biomarkers in patients treated for three months with etoricoxib, celecoxib, ibuprofen, and placebo. Arch Drug Inf 2008;1:4-13.

24. Curtis SP, Bockow B, Fisher C, Olaleye J, Compton A, Ko $\mathrm{AT}$, et al. Etoricoxib in the treatment of osteoarthritis over 52-weeks: a double-blind, active-comparator controlled trial [NCT00242489]. BMC Musculoskelet Disord 2005;6:58.

25. Gottesdiener K, Schnitzer T, Fisher C, Bockow B, Markenson J, Ko A, et al. Results of a randomized, dose- ranging trial of etoricoxib in patients with osteoarthritis. Rheumatology (Oxford) 2002;41:1052-61.

26. Leung AT, Malmstrom K, Gallacher AE, Sarembock B, Poor G, Beaulieu A, et al. Efficacy and tolerability profile of etoricoxib in patients with osteoarthritis: A randomized, double-blind, placebo and active-comparator controlled 12week efficacy trial. Curr Med Res Opin 2002;18:49-58.

27. Puopolo A, Boice JA, Fidelholtz JL, Littlejohn TW, Miranda $\mathrm{P}$, Berrocal A, et al. A randomized placebo-controlled trial comparing the efficacy of etoricoxib $30 \mathrm{mg}$ and ibuprofen $2400 \mathrm{mg}$ for the treatment of patients with osteoarthritis. Osteoarthritis Cartilage 2007;15:1348-56.

28. Reginster JY, Malmstrom K, Mehta A, Bergman G, Ko AT, Curtis SP, et al. Evaluation of the efficacy and safety of etoricoxib compared with naproxen in two, 138-week randomised studies of patients with osteoarthritis. Ann Rheum Dis 2007;66:945-51.

29. Wiesenhutter CW, Boice JA, Ko A, Sheldon EA, Murphy FT, 
Wittmer BA, et al. Evaluation of the comparative efficacy of etoricoxib and ibuprofen for treatment of patients with osteoarthritis: A randomized, double-blind, placebo-controlled trial. Mayo Clin Proc 2005;80:470-9.

30. Yoo MC, Yoo WH, Kang SB, Park YW, Kim SS, Moon KH, et al. Etoricoxib in the treatment of Korean patients with osteoarthritis in a double-blind, randomized controlled trial. Curr Med Res Opin 2014;30:2399-408.

31. García Rodríguez LA, Barreales Tolosa L. Risk of upper gastrointestinal complications among users of traditional NSAIDs and COXIBs in the general population. Gastroenterology 2007;132:498-506.

32. Nussmeier NA, Whelton AA, Brown MT, Langford RM, Hoeft A, Parlow JL, et al. Complications of the COX-2 inhibitors parecoxib and valdecoxib after cardiac surgery. $\mathrm{N}$ Engl J Med 2005;352:1081-91.

33. Warner TD, Mitchell JA. Cyclooxygenases: new forms, new inhibitors, and lessons from the clinic. FASEB J 2004;18:
790-804.

34. Dallob A, Hawkey CJ, Greenberg H, Wight N, De Schepper $\mathrm{P}$, Waldman S, et al. Characterization of etoricoxib, a novel, selective COX-2 inhibitor. J Clin Pharmacol 2003;43:57385.

35. Lin HY, Cheng TT, Wang JH, Lee CS, Chen MH, Lei V, et al. Etoricoxib improves pain, function and quality of life: results of a real-world effectiveness trial. Int J Rheum Dis 2010;13:144-50.

36. Turajane T, Wongbunnak R, Patcharatrakul T, Ratansumawong K, Poigampetch Y, Songpatanasilp T. Gastrointestinal and cardiovascular risk of non-selective NSAIDs and COX-2 inhibitors in elderly patients with knee osteoarthritis. J Med Assoc Thai 2009;92 Suppl 6:S19-26.

37. Sutton AJ, Cooper NJ, Lambert PC, Jones DR, Abrams KR, Sweeting MJ. Meta-analysis of rare and adverse event data. Expert Rev Pharmacoecon Outcomes Res 2002;2:367-79. 